\title{
CRIOLLOS ANTE EL 98: LA CAMBIANTE IMAGEN DEL DOMINIO ESPAÑOL DURANTE SU CRISIS Y CAIDA EN PUERTO RICO, 1889-1899
}

\author{
POR
}

ASTRID CUBANO IGUINA

Universidad de Puerto Rico, Río Piedras

Los criollos de finales del siglo XIX en Puerto Rico en sus escritos evocaron con frecuencia el lugar común de la España hidalga y heroica. Esa España era fuente de inspiración para sus mayores logros y justificación de sus aspiraciones de poder en la sociedad colonial. A la vez, criticaron la España de los privilegios y las oligarquías con tono regeneracionista y crítico. Se declaraban auténticamente españoles, expresando su sincero afecto a España. A la vez, mediante alegatos racistas sobre la superioridad anglosajona, asumieron la nueva dominación colonial estadounidense como un deber impuesto por la razón.

Fijar la idea que tenían de España los "criollos" de los últimos tiempos del dominio español, obliga primero a definir quiénes son los diseñadores de esa imagen, o qué es un criollo, a efectos de este trabajo. Los aspectos del complejo objeto de observación -la España de fin de siglo- que cautivaron la imaginación de los criollos, dependían de la experiencia, los conocimientos y las intenciones de los propios observadores. En última instancia, el tema de estudio son los criollos, y la España que dibujan nos sugiere sus preocupaciones y metas. Estas son sumamente diversas, por lo que la imagen proyectada cambia, obligándonos a perseguir un objetivo en constante movimiento. A veces la imagen se ve vinculada a propuestas políticas muy conscientes. Otras veces surge una España que alude preocupaciones sociales mucho menos conscientes. Este trabajo no agota el evidentemente extenso tema. Sólo proporciona algunos de los 
distintos tipos de imagen que afloraron en la prensa y otros escritos de la época.

\section{DEFINICIÓN DE CRIOLLOS}

Los escritores de fin de siglo en Puerto Rico usaron el término "criollo" vagamente como equivalente de los habitantes nacidos en la isla (legalmente considerados españoles), para distinguirlos de los peninsulares, o españoles nacidos en la península. Sin embargo, es evidente la necesidad de aludir a cualidades más específicas.

Historiadores, antropólogos y otros estudiosos desde las postrimerías del Imperio español en la América continental hasta nuestros días, al estudiar la tradicional división de castas, han observado que la palabra "criollos" tuvo originalmente un sentido peyorativo por referirse a españoles "nacidos y criados en la tierra" y, por lo tanto, racial y culturalmente "contaminados" por la diversidad étnica novomundista. El término se usó con más frecuencia durante los últimos tiempos del Imperio para referirse a la minoría nativa, descendiente de españoles, de posición acomodada, culta y predominantemente blanca, aunque ni la ascendencia racial ligeramente mixta, ni la mengua del patrimonio familiar, necesariamente fueron motivo de exclusión. El segundo factor definitorio era de tipo político, ya que los criollos se consideraban a sí mismos los líderes naturales del país, una élite educada y con capacidad administrativa que se encontraba marginada del poder. Representaban un movimiento de afirmación nativista que intentaba, con franca vocación de hegemonía política, establecer la distinción frente a los recién llegados peninsulares que se percibían como representantes de la dominación metropolitana ${ }^{1}$.

1 Ver John Lynch, The Spanish-American Revolutions, 1808-1826, New York, W.W. Norton, 1973, pp. 1-36; Magnus MörNER, La mezcla de razas en la historia de America Latina, Buenos Aires, Paidos, 1969; James LOCKHART y Stuart B. SCHWARTZ, Early Latin America, Cambridge University Press, 1983, pp. 132, 321-22, 327 y 423; Nicholas CANNY y Anthony PAGDEN, Colonial Identity in the Atlantic World, Princeton University Press, 1989, pp. 9, 12, 61-62, 90-91; para una definición de la época ver Lucas ALAMÁN, Historia de Méjico, México, Editorial Jus, 1942, reimpresión de edición de 1849-52, 1ra. parte, Libro Primero, Capítulo 1, p. 16.

R. I., $1997, \mathrm{n}^{\circ} 211$ 
En el Puerto Rico de finales del XIX esa postura la asumían los políticos autonomistas. Al tomar el nombre de criollos (algo que hacían ocasionalmente) se autorizaban en el papel de representantes de todos los habitantes nacidos en la isla, dentro de la estructura imperial española. Constituían un grupo letrado compuesto por abogados, maestros, periodistas, empleados públicos y profesionales diversos, provenientes de familias terratenientes o comerciantes, muchas veces venidas a menos. Es difícil concluir respecto a si los criollos habían sido empujados a la frontera inferior de su clase por la crisis del sector exportador insular, por la división entre muchos herederos de las fortunas familiares forjadas durante la etapa de expansión de la economía azucarera, o simplemente, por la falta de vocación para los negocios (que muchos admitían) y la entrega de las propiedades a administradores menos interesados. ${ }^{2}$ Muchos seguramente disponían de las rentas de algún patrimonio familiar. La mayoría combinaba las funciones profesionales con las actividades periodísticas y literarias, aunque hubo algunos que fueron exclusivamente intelectuales. Como intelectuales de fin de siglo, su lenguaje con frecuencia denota la perspectiva radical y democratizante.

En la definición de lo criollo en Puerto Rico tendió a prevalecer lo cultural y político sobre la cuestión más técnica del lugar de nacimiento. Así, los historiadores llaman al periodista asturiano Manuel Fernández Juncos "español acriollado" gracias a su colaboración en el desarrollo de las letras puertorriqueñas y por su identificación con la causa liberal y con la demanda de reformas políticas que dejasen el gobierno en manos de los "hijos del país"3.

Trazar las fronteras del movimiento "criollo" es siempre complicado. Naturalmente, no todos los nativos letrados, descendientes total o parcialmente de españoles, eran autonomistas. Había políticos como Balbás Capó, periodista conservador nacido en Ponce,

2 Para un ejemplo de esto último ver Luis M. DíAz SolER, Rosendo Matienzo Cintrón. Orientador y guardián de una cultura, 2 v., San Juan, Instituto de Cultura Puertorriqueña, 1960, v. 1, p. 128. Ver otro ejemplo en Quintín NEGRón SANJURJo, Los primeros treinta años de la vida de Luis Muñoz Rivera, San Juan, Fundación Luis Muñoz Marín, 1993; Repecto a los temas de la crisis y el empobrecimiento de los criollos ver Gervasio L. GARCía, Historia crítica, historia sin coartadas, Río Piedras, Ediciones Huracán, 1985, p. 55; A. Cubano Iguina, El hilo en el laberinto, Río Piedras, Ediciones Huracán, 1990.

3 José Antonio Torres Morales, Manuel Fernández Juncos. Antología de sus obras, México, Editorial Orión, 1960, p.11. 
Puerto Rico, quien escribía, no como criollo marginado del poder, sino desde el poder, como miembro activo del Partido Español Incondicional $^{4}$. Sin embargo, Balbás Capó destacó por su defensa de los intereses nativos (que no eran pocos) dentro de esa entidad ${ }^{5}$.

En el otro extremo de la escala socio-política tendríamos que considerar al grupo letrado subalterno. Está el ejemplo de la líder anarquista y feminista Luisa Capetillo, de piel oscura, nacida en Puerto Rico, hija de un inmigrante vasco (obrero del mundo del espectáculo) y una mujer francesa de las islas. Capetillo, quien contaba entre sus referencias cultas a la obra del republicano español Emilio Castelar, sólo tras arduo debate podría ser analizada como voz criolla porque su propuesta política se desenvolvió al margen de esa postura ${ }^{6}$. En cambio, el poeta Francisco Gonzalo Marín, de condición racial y social muy similar a la de Capetillo (hijo de artesano y madre extranjera de las islas) y compartiendo una misma actitud radical en política, estuvo expresamente alineado del lado "criollo" y formó parte del grupo autonomista ${ }^{7}$.

En definitiva, este trabajo se basa en voceros y publicaciones de autonomistas, criollos en la medida en que aspiraron a dirigir la vida política y cultural del país, y en escritos de algunas criollas que quisieron compartir con los criollos la tarea de diseñar la imagen nacional española. Se intenta recoger la imagen de otra imagen: la imagen de España que proyectan los que se ven a sí mismos como criollos.

\section{NACIONALIDAD, LENGUA Y RAZA}

Los criollos de fin de siglo, por lo general, asumían la nacionalidad española de forma consciente. "Somos españoles", había escrito José Pablo Morales en 1876, "enteros y completos por deber, por derecho, por conveniencia y por afección; ciudadanos españoles por

\footnotetext{
4 Modesto Gotay, Hombres ilustres de Puerto Rico, Barcelona, Rumbos, 1960, p. 17

5 Lidio Cruz Monclova, Historia de Puerto Rico (siglo XIX), 3v., Río Piedras, Editorial Universidad de Puerto Rico, v. 3, pp. 90 y 139.

6 Norma Valle Ferrer, Luisa Capetillo. Historia de una mujer proscrita, Río Piedras, Editorial Cultural, 1990; Julio RAMOS, ed., Amor y anarquía. Los escritos de Luisa Capetillo, Río Piedras, Ediciones Huracán, 1992, p. 18 y 41.

7 Cayetano Coll y Toste, Puertorriqueños ilustres, Barcelona, Rumbos, 1963, p. 328, Francisco CADILLA, Los ochocentistas, Barcelona, Rumbos, 1961.
} 
todos cuatro costados, a pesar de los matices de este $\mathrm{u}$ otro color físico o político"8. El deber y el derecho de ser españoles quedaban establecidos por la ley; la conveniencia, el propio José Pablo Morales la había articulado privadamente en una carta de 1865 a José Julián Acosta en los siguentes términos:

Creo que Puerto Rico se ve rodeado de peligros que le hacen necesario el apoyo de la metrópoli; que pensar en la independencia no es más que un sueño ilusorio; obrar para conseguirla lanzarnos en una carrera de aventuras cuyo término sería el caos...y cómo arrojarnos en brazos de los yankees equivaldría al suicidio, debemos ser españoles por convencimiento, ya que lo somos por afecto9.

España era, en el plano más razonado, un "apoyo" indispensabla para la supervivencia de los criollos frente al caos social. "La anarquía produce casi siempre despotismo", reflexionaba el médicohistoriador Cayetano Coll y Toste años después con el modelo bonapartista en mente, aunque puede pensarse que Haití era una referencia más inmediata ${ }^{10}$. Si el cambio social alarmaba, todavía más amenazadora se veía la absorción de los Estados Unidos, siguiendo la tradición que había establecido el escritor cubano, José Antonio Saco $^{11}$.

El afecto era un sentimiento más espontáneo y aparentemente la menos racional de las alegadas causas de adhesión a España. Estaba vinculado a percepciones de afinidad cultural y a un conjunto de ideas sobre la raza y las naciones. La conferencia del abogado y educador (krausista de formación ${ }^{12}$ ) Manuel Elzaburu Vizcarrondo

8 José Pablo Morales, Misceláneas históricas, San Juan, Tip. La Correspondencia, 1924, p. 53.

9 José Pablo MoRALEs, Ideas de un jíbaro sobre la reforma, (manuscrito) 1865, Colección Acosta, Centro de Investigaciones Históricas, Universidad de Puerto Rico.

10 Edna Coll, Cayetano Coll y Toste. Sintesis de estímulos humanos, Río Piedras, Editorial Universidad de Puerto Rico, 1970, p. 51.

11 Ver Gordon K. LEWIS, Main Currents in Caribbean Thought, Baltimore, The Johns Hopkins University Press, 1983, pp. 152-153; Luis MARTínez FERNÁNDEZ, Torn Between Empires. Economy, Society, and Patterns of Political Thought in the Hispanic Caribbean, 1840-1878, Athens, Georgia, The University of Georgia Press, 1994.

12 Durante sus años universitarios, Elzaburu estuvo en contacto con la juventud democrática de España. Hizo la carrera de derecho en la Universidad Central de Madrid de 1867-1873, donde fueron sus dos más apreciados maestros Laureano Figuerola, jurisconsulto y economista catalán, y Emilio Castelar. Figuerola presidió su tribunal examinador y 
ante el Ateneo Puertorriqueño, titulada "El sentimiento de nacionalidad" (1889), contribuyó a precisar esas nociones y a aclarar el problema de las lealtades en conflicto entre la nación y la "región". El concepto de región adquiría en esos años una importancia crucial en la discusión política española debido a la revitalización de los movimientos de afirmación de las diversas nacionalidades que ocupaban el territorio español, especialmente el catalanismo ${ }^{13}$.

Elzaburu distingue los tipos de afecto: "la patria regional es más íntima, se ama con pasión". La nación (España) o la patria "total" implica una "afección de grado superior" y más "sublime". Elzaburu primero cita el dogma incuestionable de la adhesión a la nación: "La religión, el arte y la patria son de un orden superior, metafísico, antes buenos para sentidos que no para pensados." Pero es evidente que su intención es "pensar" o analizar el lazo sentimental que une a Puerto Rico con España. El sentimiento de nacionalidad se basa en la afinidad y "no es más que el estímulo de mayor grandeza, la ambición legítima de formar un gran cuerpo, y el honor de sostener gloriosa esa misma entidad.." El amor más fuerte es el amor propio, que se extiende luego a la familia, a la provincia, "se prolonga más tarde hasta la afinidad con que nos reconocemos los individuos de una misma raza y concluye por alcanzar la humanidad." Los hijos de la raza latina (tronco del que se pensaba surgía España), añade Elzaburu, "nos sentimos orgullosos de nuestro destino cumplido en la historia" y "soñamos, como los de las demás razas, en cumplir grandes proezas ${ }^{1466}$.

El amor a España, pensaban los criollos, era algo que podía ser compartido espontáneamente por todas las clases sociales. Así, en su función de historiador, Salvador Brau observa que durante el ataque inglés a Puerto Rico de 1797 "blancos y negros, propietarios y esclavos", sin vacilaciones y "machete en mano" habían defendido la soberanía española. Interpreta Brau que ésta fue una muestra de

\footnotetext{
en su bufete obtuvo Elzaburu sus primeras experiencias de trabajo. Luis HERNÁNDEZ AQuiNo, "Personalidad y obra de Manuel Elzaburu Vizcarrondo", en Manuel Elzaburu Vizcarrondo. Prosas, poemas y conferencias, San Juan, Instituto de Cultura Puertorriqueña, 1971, pp. 5-6.

13 Horst HinA, Castilla y Cataluña en el debate cultural, 1714-1939, Barcelona, Ediciones Península, 1986.

14 Manuel Elzaburu VizCARrondo, "El sentimiento de nacionalidad", en Manuel Elzaburu Vizcarrondo. Prosas, poemas y conferencias..., pp. 285, 297-298, 302-303.
}

R. I., 1997, $\mathrm{n}^{\circ} 211$ 
afecto a España, como el "Dos de Mayo" (fecha del levantamiento popular en España contra la invasión napoleónica), un espontáneo levantamiento a favor de la integridad nacional, que no se produjo, en cambio, entre los habitantes de la isla de Trinidad ${ }^{15}$. No explicó Brau las razones de esto último; lo que le interesaba era destacar que el afecto a España podía y debía ser un elemento efectivo de cohesión social y legitimación.

España era, pues, para los criollos, fuente de nacionalidad y raza, un elemento esencial para su propia realización y para la de todos los habitantes de la isla. Gracias a España, se accedía a la "familia latina ${ }^{16 " .}$. A tono con su visión providencialista de la historia, y mediando a veces los matices del lenguaje krausista y universalista, España era la vía para alcanzar un "destino" enaltecedor. La supuesta "grandeza" de su pasado era una promesa de futuro. El carácter nacional proclamado "hidalgo"17 cautivaba la imaginación de estos escritores que se veían de alguna manera reflejados en esa España. Con el optimismo que les daba esa sensación de semejanza, sumado a su firme creencia en la efectividad de la educación, se mostraban convencidos de que los puertorriqueños aspirarían a ser parecidos a esos míticos españoles del "Dos de mayo".

El pronombre "nuestro" se aplicaba con comodidad para referirse a los elementos compartidos con la metrópoli: Brau notaba como los pueblos hispanoamericanos conservaban "nuestra raza", "nuestra religión", "nuestras costumbres" y "nuestro idioma"18. Esa identificación llegaba incluso a darse en la discusión de asuntos de política exterior española. Esto no sorprende en el caso del periodista nacido en Puerto Rico, Luis Bonafoux, quien residía en Madrid y estaba totalmente inmerso en la intelectualidad madrileña de la época. Bonafoux criticaba con desenfado "nuestra" política de "sumisa amistad" con el gobierno alemán ${ }^{19}$. Sin embargo, el "nosotros" se

\footnotetext{
15 Salvaor BraU, Ensayos (Disquisiciones sociológicas), Río Piedras, Edil, 1972, p. 168.

16 Para el tema de la "familia latina" ver Maria Teresa MARTínEZ BLANCO, Identidad cultural de Hispanoamérica. Europeismo y originalidad americana, Madrid, Universidad Complutense, 1988, pp. 51-59.

17 BRAU [15], p. 186.

18 Ibid., pp. 193 y 211.

19 Luis Bonafoux, Literatura de Bonafoux, San Juan, Instituto de Cultura Puertorriqueña y Editorial de la Universidad de Puerto Rico, 1989, reimpresión de edición de 1887, p. 75 .
} 
observa también en las discusiones de Muñoz Rivera sobre el mismo tema, al aludir, por ejemplo, a la situación "que se nos presentó cuando la cuestión de las Carolinas." 20

La conmemoración del Cuarto Centenario del descubrimiento de América fue ocasión de afirmación de la "familia latina", de reconocimientos a la "noble España, tierra de héroes" y de proclamar "eterna gloria a Isabel la Católica que impulsó a realizar tan colosal empresa." según afirmó J. A. Daubón en una carta al editor de $L a$ Correspondencia ${ }^{21}$. El Cuarto Centenario del descubrimiento de Puerto Rico en 1893 sirvió a la escritora criolla Ana Roqué de estímulo para plasmar su propia definición de la palabra "patria." Roqué reproducía una versión de la España madre protectora que diseñó Morales y que Elazaburu dotó de elementos providencialistas:

¿Qué es patria? Si a mi cabeza lo pregunto me responde: Patria es el Universo; todos los hombres, aún los que habitan en esa esfera de luz de nuestro cielo, son nuestros hermanos; mas, si mi corazón contesta, patria, dice, es aquélla nación heróica que nos hace enorgullecer con sus grandezas, y nos protege con su pabellón; es la matrona hidalga que nos legó su idioma, costumbres y cultura; y por último la región esplendorosa, rico girón de tierra castellana, de brillante sol, y sin igual verdura, en que nos fue dado nacer...22

Cuando le comparaban con la "raza anglo-sajona", los criollos percibían a España vulnerable. Presentaban actitudes titubeantes ante la influencia cultural "anglo-sajona":

Nosotros, que en medio de una grande admiración por las altas cualidades de esa raza (anglo-sajona), temblamos por las imitaciones irreflexivas que de sus modos de ser político sociales, puedan hacerse en nuestra patria, también nos dejamos llevar á veces de una vaga idolatría hacia la vieja Inglaterra o hacia los jóvenes Estados Unidos ${ }^{23}$.

20 La Democracia, 14 de marzo de 1996.

21 La Correspondencia, 10 de octubre de 1892.

22 Ana RoQUÉ, Revista Puertorriqueña. Album del Centenario de Puerto Rico, 1893; sobre Ana Roqué ver María de Fátima BARCELó MILlER, Voto, colonialismo y clase: la lucha por el sufragio femenino en Puerto Rico, 1896-1935, Río Piedras, Centro de Investigaciones Sociales/Ediciones Huracán, en prensa, caps. 1 y 2.

23 Ezequiel MARTíneZ QUINTERO, La Ilustración Puertorriqueña, año 1, núm. 1, 10 de abril de 1892 .

R. I., $1997, \mathrm{n}^{\circ} 211$ 
El inicio de la Guerra de Independencia de Cuba en 1895, y las tensiones entre España y Estados Unidos, que se intensificaron en 1897, hicieron incrementar los temores de los criollos y sus actitudes de adhesión se acentuaron. En el verano de 1897 los autonomistas congregados entonces en el Partido Liberal efectuaron la reconciliación oficial con el Cuerpo de Voluntarios, institución de orden público compuesta por ciudadanos e identificada hasta ese momento con el Partido Incondicional Español. "Todos los españoles sostenedores de la integridad nacional" tendrían que respaldar a ese indispensable cuerpo ${ }^{24}$.

Las percepciones racistas y darwinistas de la sociedad que compartían los criollos, útiles para justificar sus argumentos más optimistas y su derecho natural a encabezar la marcha enaltecedora del país, ahora se volvían en su contra. El abogado y escritor autonomista Rosendo Matienzo Cintrón calculaba que si Estados Unidos ocupaba a Puerto Rico la pujante fortaleza de la "joven nación sajona" obligaría a Puerto Rico a asimilar los "gérmenes de vida" de la madre tierra (España). De lo contrario, los puertorriqueños, temía Matienzo, serían "depauperados" y estarían condenados a "desaparecer por natural selección"25.

En el fondo inconsciente, el lenguaje de la raza española implicaba algo más que la adopción de una jerarquía biológica. También era simbólico. Raza representaba cosas muy concretas, como la letra y la ley; instituciones compartidas y disfrutadas principalmente por la minoría criolla, tradiciones que les favorecían y en las que se asentaba su posición social. Esa era la "sangre de la raza española" o "los gérmenes de vida" que llevaban dentro, capaces de resistir mayores impactos, y lo único que podría salvarles de la absorción anglo-sajona ${ }^{26}$. El contratiempo más problemático era que la mayoría de los puertorriqueños se encontraba al margen o desinteresada de esa letra y de esas leyes y tradiciones, que ya eran las de los criollos. Por eso se percibía a la población puertorriqueña débil y expuesta a sucumbir ante presuntos nuevos grupos dirigentes del norte.

24 DíAz Soler [2], v. 1, p. 128.

25 Ibid., pp. 142-43.

26 Loc. cit. 


\section{CONTRADICCIONES CRIOLLAS Y VOCES DISIDENTES}

Las presiones de la censura (que en más de una ocasión provocó el cierre de algún periódico autonomista) y la necesidad de los criollos de evitar acusaciones de separatistas, que obligaba a incorporar frases de adhesión, hacen que la imagen que se proyecta de España se encuentre necesariamente mediatizada por preocupaciones ajenas al texto y no expresadas. La supuesta "hidalguía característica de la raza española" y la "grandeza" de España a veces eran frases aduladoras, con un toque de ironía, que antecedían demandas de reforma política ${ }^{27}$.

Se percibe el esfuerzo, como estrategia política, por arrebatar a los incondicionales españolistas el monopolio del discurso de la integridad nacional. "A España no la representan en las Antillas los pocos obstruccionistas de nuestro adelanto...," decía Elzaburu Vizcarrondo $^{28}$. También Morales había intentado establecer la compatibilidad entre progresismo criollo y adhesión a España: "Si quereis servir a nuestra querida patria España, amad el progreso"29.

Los criollos intentaban incluso demostrar que eran más españoles que los nacidos en regiones peninsulares donde existían lenguas maternas distintas. Salvador Brau usó ese argumento para advertir que Puerto Rico merecía los mismos derechos que todas las otras regiones: “...en estas escuelas jíbaras en que cursé rural enseñanza, no se enseñaba otra gramática que la de la Real Academia Española..."30

Era difícil ocultar los problemas que presentaba la concesión incompleta de derechos constitucionales a los antillanos. La censura obligaba a Elzaburu Vizcarrondo a aclarar que no tenía la intención de invadir "los espacios que le están vedados..a nuestra lucubración o actividad intelectual." Pero más adelante fundamentaba su idea de nacionalidad en los argumentos de Rousseau. La nación era "la comunidad más completa en el derecho, la participación en el gobierno, la facultad de expresar la voluntad de todos." Ese estado "no se alcanza hasta que la voluntad del pueblo se constituye en nación,

\footnotetext{
27 Brau [15], p. 186.

28 ElZABURU VizCARRONDO [14].

29 José Pablo MORALES, “A la juventud puertorriqueña", La Ilustración Puertorriqueña, año 1 , núm. 4, 25 de mayo de 1892 .

30 BRAU [15], p.165.
}

R. I., 1997, n. $^{\circ} 211$ 
hasta que ese mismo pueblo no se pone en actividad, ejercitando sus derechos políticos." Lo contrario sería el "despotismo, que no reconoce ciudadanos sino esclavos." La protesta criolla se escapaba a la primera oportunidad ${ }^{31}$.

El discurso criollo asumía las más diversas formas. La denuncia podía expresar los compromisos que sentían respecto de grupos populares en desventaja ${ }^{32}$. El "pueblo", del pasado o del presente, fue objeto frecuente de compasión. El 19 de noviembre de 1893 (Cuarto Centenario del descubrimiento de Puerto Rico) la poetisa Fidela Mateu de Rodríguez se proyecta a sí misma como española de la tierra y cumple su deber de denunciar el exterminio de la población indígena del Puerto Rico de entonces con un breve comentario titulado "¡Pobres Indios!”:

"Vinieron, se nos dice, a darles vida, religión y costumbres, pero los exterminaron. ¿Celebramos pues el centenario de una gloria o de un crimen?... ¿Debe llenarnos esta felicidad de remordimientos?... Yo soy española, yo desciendo de los que, debiendo civilizaros y amaros, os exterminaron y en este día de recuerdos, no puede el alma acallar los crueles remordimientos de mi raza....33

La crisis de la economía exportadora, la inflación, la miseria y la enfermedad en los campos eran temas que preocupaban a escritores como Salvador Brau, Manuel Zeno Gandía y Luis Muñoz Rivera. ${ }^{34}$ Tales temas subyacían el proyecto político criollo basado en el sufragio universal masculino y fundamentado a su vez en la convicción que tenían de poder conseguir mayor bienestar para el país. Voceros autonomistas como La democracia, expresaban con frecuencia las quejas contra un régimen que sentían era despótico y

31 Elzaburu VizCARrondo [14], pp. 276-279; para el nacionalismo político en Rousseau ver Josep R. LlOBERA, El dios de la modernidad. El desarrollo del nacionalismo en Europa occidental, Barcelona, Anagrama, 1996, pp. 211-219.

32 Ver la síntesis que proporciona Mariano NEGRón PORTILLO, Las turbas republicanas, 1900-1904, Río Piedras, Ediciones Huracán, 1990, pp. 18-52.

33 Fidela M. de RodrígueZ, Revista Puertorriqueña. Album del Centenario de Puerto Rico, 1893; Fidela Mateu (o Matheu) de Rodríguez nació en Arecibo, donde fue discípula del autonomista Ramón Marín y de Rosenda Padilla, hermana del médico y poeta José Gualberto Padilla ("El Caribe"). Joaquín FreIRE, Presencia de Puerto Rico en la historia de Cuba, San Juan, Ed. Cultural Puertorriqueña, 1986.

34 BRAU, [15]; Manuel Zeno Gandía, La charca, Barcelona, Ed. Puerto, 1973. 
opresivo, y un obstáculo al desenvolvimiento económico de la isla ${ }^{35}$. El sistema colonial español, explicará Muñoz Rivera sucintamente años después, "estancaba las energías productivas y atrofiaba las fuerzas intelectuales del pueblo puertorriqueño, aplastándolas con la pesadumbre de un despotismo absurdo y centralizando todas las iniciativas en manos del gobierno"36.

En medio de la crisis intensa del colonialismo español debida a la guerra de Cuba, la imagen de España esporádicamente dejaba de ser la de "noble hidalga" para tornarse en la España famélica: "Media España está sin comer y quiere filtrarse en el presupuesto. Después el presupuesto se filtrará en las luchas de media España"37.

Una ley electoral de comienzos de 1893 dio a los criollos la ocasión de expresar su sensación de marginación y ponerse a sí mismos el nombre de "españoles de tercera." 38 La primera clase correspondía a los españoles de la península que ejercían el sufragio universal (masculino, aunque los criollos lo percibieron como universal), y la segunda, a los cubanos, a los que se concedía el derecho al voto para diputados a Cortes a los contribuyentes al fisco con más de 5 pesos al año. En cambio, los estadistas españoles prescribieron que para Puerto Rico se fijase la cuota en 10 pesos, justificados por los argumentos de los incondicionales más conservadores que aseguraban que en Puerto Rico la cuota de 5 pesos era equivalente al sufragio universal ${ }^{39}$.

El caciquismo político que caracterizaba el sistema democrático en España y era la base, no sólo de los turnos de liberales y conservadores en el poder, sino del control de toda la vida política peninsular desde Madrid ${ }^{40}$, permitía a los criollos proyectar la imagen de una España anquilosada en el pasado y paralizada por los privilegios

\footnotetext{
35 NEGRÓN PORTILLO [32].

36 DíAz SOLER [2], p. 166.

37 La Democracia, 1 de agosto de 1895.

38 BRAU [15], p.165-168; ver alusiones similares a la condición de "españoles de tercera" en varios artículos de Luis MUÑOZ RIVERA, La democracia, 1993.

39 Astrid Cubano Iguina, "El autonomismo en Puerto Rico: notas para la definición de un modelo de política radical" en Consuelo NARANJO, Miguel A. PUIG-SAMPER y Luis Miguel García MoRA, eds., La nación soñada: Cuba, Puerto Rico y Filipinas ante el 98, Madrid, Doce Calles, 1996, pp. 405-416

40 Ver José VARELA ORTEGA, "Sobre la naturaleza del sistema político de la Restauración" en Miguel Artola et al., Nación y Estado en la España liberal, Madrid, Editorial Noesis, 1994, pp. 169-194.
} 
e intereses oligárquicos. En Puerto Rico, sin embargo, el caciquismo consolidaba al Partido Incondicional en el poder. Dejaba a los oligarcas incondicionales un enorme margen de acción libre en el ámbito local y era uno de los motivos de ataques criollos más concretos al dominio español ${ }^{41}$.

Para los autonomistas era urgente desarrollar mecanismos de atracción del "jíbaro", antes de que éste atendiese a las "tentadoras insinuaciones" a la rebelión que sigilosamente solicitaban su atención $^{42}$. Había que incorporar a la masa rural a la actividad partidista. Era urgente subir al poder, pero la población rural con derecho al voto (aún con la cuota electoral más baja de 5 pesos de contribuciones) no valoraba las razones autonomistas, ya por falta de "espíritu cívico", ya por las densas redes de influencia (económica y política) que tejía la maquinaria electoral incondicional en el país. España se mantenía sorda, suspicaz e inflexible ante los criollos.

La crítica a España se expresaba casi siempre con el pronombre "nosotros", sin abandonar la perspectiva española. Se mantenía en la frontera de lo permitido, como autocrítica rabiosa y regeneracionista. Así, Luis Muñoz Rivera escribía:

Mientra que fía el mundo su adelanto y su grandeza en las ideas nuevas,..nosotros damos la espalda al sol...No se trata exclusivamente de los asuntos coloniales. Observad la Península. Mientras en casi todos los pueblos que la rodean los estadistas beben sus inspiraciones en las fuentes populares, allí están los nuestros, divorciados de la sociedad por ellos dirigida ${ }^{43}$.

Mas, invariablemente, los criollos, se cuidaban de no empañar el espejo en que buscaban su propia imagen:

Es España pueblo robusto que parece pueblo enclenque por virtud de los procedimientos gubernamentales ${ }^{44}$.

\footnotetext{
41 Ver por ejemplo, Revista Puertorriqueña. Album del Centenario de Puerto Rico, 1893; El País, 5 de enero de 1897. y numerosos artículos en La Democracia, 1895 y 1896.

42 DíAz SOLER [2], p. 123.

43 La Democracia, 2 de marzo de 1896.

44 Ibid., 15 de mayo de 1896.
} 
El "nosotros" en ocasiones se hacía exclusivamente regionalista y puertorriqueño, especialmente si se trataba de sostener argumentos relacionados con el tema de la descentralización del poder. Así, para defender la autonomía presupuestaria municipal se aludía a la "destartalada marcha que ha conducido la vida municipal al deplorable estado en que se halla," y se protestaba por alegadas apropiaciones de fondos: "¿de dónde ha de venir a nadie el poder de meter la mano clandestinamente en nuestros bienes sin nuestra autorización expresa?"45

Debe quedar claro que los criollos no formaban una sola opinión en el tema de España. La España "heroica" que dibujaron algunos (quizás la mayoría) no era la única referencia elevada que servía de apoyo. Por ejemplo, criollos como Manuel Romero Haxthausem de Arecibo, preferían celebrar el Cuarto Centenario del descubrimiento de América, "patria de hombres como Washington y Bolívar", sin mencionar a España ${ }^{46}$.

Afirmaciones de este tipo rayaban peligrosamente en la propaganda independentista y anexionista, y eran raras, obviamente porque representaban un riesgo de intervención de las autoridades. La perspectiva independentista indudablemente tenía un lugar entre los criollos. Textos de 1899, tras la caída del régimen español, revelan expectativas de afirmación nacional independiente para Puerto Rico. Para Enrique Marques, por ejemplo, "el exterminio de España" era un hecho inevitable que "había de venir del Norte o había de resolverse en el trópico.." En Puerto Rico, reconoce Marques, España era "más fuerte que los Estados Unidos." Pero el empeño de Marques en colocar a Puerto Rico en la ruta inexorable de la libertad, le llevan a desarrollar la tesis providencialista de la liquidación inevitable del colonialismo español: "Claro se ve que Puerto Rico no estaba en la misma situación de Cuba; pero estaba como ésta en el plano inclinado que había de conducirla como Cuba al logro de soñados y próximos ideales de personalidad" 47 .

El anexionismo en Puerto Rico se desarrollaba entre criollos que familiarizados con la cultura norteamericana y por conveniencia (algunos intereses azucareros y grupos urbanos que no encontraban

45 El País, 2 de enero de 1897.

46 La Correspondencia, 12 de octubre de 1892.

47 Enrique J. MARQueS, Cuba y Puerto Rico, Puerto-Rico, Imprenta de El País, 1899. 
soluciones a sus problemas bajo el sistema colonial español) favorecían la asimilación total a los Estados Unidos. Como no era una alternativa real, y dependía más del propio Estados Unidos que de Puerto Rico, puede definirse sólo como una predisposición, o un discurso de simpatía por los Estados Unidos y sus instituciones que emerge tenuemente detrás de las discusiones de 1897-98 en torno a la reforma colonial ${ }^{48}$.

\section{CRIOLlOS ANTE EL 98}

Los criollos vivieron la breve y accidentada experiencia de gobierno autonómico, en medio de las tensiones que condujeron a la Guerra Hispanoamericana y en una situación de crisis económica y social. Prevalecían sentimientos de agradecimiento a España, al menos entre la mayoría victoriosa del Partido Liberal. Gracias a un decreto ministerial del gobierno de Sagasta, en Puerto Rico regían la Carta Autonómica y el sufragio universal masculino. Otras órdenes habían dado al liderato autonomista acceso inmediato al poder ejecutivo mediante la creación de un Gabinete, y habían permitido la sustitución de los alcaldes incondicionales con liberales para asegurar el ejercicio libre del derecho al voto. El Partido Liberal se había convertido en un partido masivo, capaz de movilizar a una mayoría popular sin precedentes en el país, la cual le llevó al contundente triunfo electoral de marzo de $1898^{49}$.

Los criollos posiblemente sospechaban una España vulnerable, militarmente incapaz de vencer al enemigo estadounidense, aunque los informes que se divulgaban desde Madrid creaban una imagen engañosa del poderío naval español. El Gabinete autonómico se solidarizó con la necesidad de España de salvar "su honra y su derecho." El discurso de la raza en su versión criolla reemergió. Se expresaba la disposición de los puertorriqueños a tomar las armas a

48 Ver Aarón Gamaliel Ramos, Las ideas anexionistas en Puerto Rico bajo la dominación norteamericana, Río Piedras, Ediciones Huracán, 1987, pp. 12-17; Astrid CuBANO IGUINA, "La política de la élite mercantil y el establecimiento del régimen autonómico en Puerto Rico", Op._cit., Boletín del Centro de Investigaciones Históricas, Universidad de Puerto Rico, 3 (1987-88), pp. 153-173.

49 Cubano Iguina [48], p.168-171. 
favor de la integridad nacional, para que no pudiese pensarse que la heroica sangre de España se degeneraba en el Nuevo Mundo:

El pueblo de Puerto Rico demostró siempre que ama la paz; demostró también que sabe mantenerse en la guerra digno de su raza y de su historia...No somos culpables de la lucha, ni la provocó nuestra tierra..Pero ni la rehuimos ni la tememos, porque sabríamos responder a la fuerza con la fuerza y probar al mundo que en este archipiélago no degenera la sangre que fecundó las campiñas de ambos hemisferios americanos en los gloriosos días de Pizarro y de Cortés ${ }^{50}$.

Incluso la oposición autonomista ortodoxa, indignados y críticos por creer que el líder liberal, Luis Muñoz Rivera, se tornaba en "caudillo" indiscutido del país, se alineaba con absoluta lealtad del lado de España ${ }^{51}$.

El periodo transcurrido entre la ocupación de Puerto Rico por las tropas estadounidenses y el traspaso del mando de manos españolas a los Estados Unidos fue breve y confuso, desde el punto de vista de las lealtades criollas. Los autonomistas poco a poco se vieron arrastrados por la ola de sentimientos favorables a la anexión a los Estados Unidos que se difundió con rapidez en las principales ciudades de la isla.

El líder liberal Cayetano Coll y Toste narró sus experiencias. Presenció desde su casa en la calle Fortaleza la ceremonia del cambio de gobierno con "hondo pesar", aturdido por el ruido de "los hurras de los adictos a los americanos."

Tuvimos que esforzarnos para sonreir con todos nuestros huéspedes y no comunicar a las personas que estaban en casa los sentimientos de nuestro corazón latino que se rebelaba contra nuestra cabeza sajona... Era el postrer adiós a la querida bandera de nuestros padres y de nuestros abuelos. Fue cruel con nosotros; inconscientemente nos flagelaban el rostro con ella muchas veces, manejada por manos injustas y profanada por manos retrógradas; $y$, a pesar de todo, la amábamos ${ }^{52}$.

\footnotetext{
50 Consejo de Secretarios del Gobierno de Puerto Rico, "Al pueblo de la colonia" en Angel Rivero, Crónica de la Guerra Hispanoamericana en Puerto Rico, New York, Plus Ultra Educational Publishers, 1973, pp. 47-48; ver también p. 132 en el tema de las noticias engañosas de la prensa en Madrid.

51 Ver Fernando Picó, 1898. La guerra después de la guerra, Río Piedras, Ediciones Huracán, 1987, p. 45.

52 Boletín Histórico de Puerto Rico, v. 6, p. 29.
}

R. I., $1997, \mathrm{n}^{\circ} 211$ 
Los criollos se sentían atrapados en la red del discurso progresista y racista de fin de siglo, que ellos mismos compartían, y que prescribía su absorción por la "vigorosa raza anglo-sajona" como clase dirigente. Coll y Toste estaba enfrascado en su lucha interna entre su "cabeza anglo-sajona" y su "corazón español."

Abundaron las manifestaciones populares de alegría ante el nuevo régimen y los testimonios antiespañoles ${ }^{53}$. Las expresiones de esperanza de prosperidad y progreso iban acompañadas de severos reproches a España, como el del criollo Francisco de Goenaga, hijo de un militar español:

"Lo menos que pudo hacer este sufrido pueblo fue lo que hizo: asistir a la festiva despedida de vuestros barcos estivados de una falange numerosísima de enriquecidos empleados importados como mercadería de lance, de libre tráfico, como si en cuatro siglos de colonización no hubiese podido la población exhuberante de la isla producir abogados, médicos, artesanos, curas obispos, intendentes, provisores generales y oficinistas suficientes para bastarse a sí misma ${ }^{54}$.

Durante los primeros meses de la dominación militar estadounidense los criollos mantuvieron un cauteloso equilibrio entre dos mundos. La Correspondencia del 25 de julio de 1899 dividió el espacio entre dos eventos dignos de conmemoración. En una columna explicaba las actividades de "la colonia española" que celebraba las tradicionales fiestas de Santiago, patrón de España. Describía los "vistosos fuegos artificiales" que se habían lanzado al amanecer y los hogares de la Capital engalanados con "las franjas de oro y grana, timbre de orgullo de la nación ibera". En otra columna, describía el programa de las "fiestas populares" que se organizaban en el puerto de Guánica para celebrar el primer aniversario de la ocupación norteamericana. Anunciaba los espectáculos públicos y recreativos que tendrían lugar en conmemoración de "la primera vez que ondeó en aquella bahía la bandera estrellada de las franjas rojas y blancas" 55 .

53 Negrón Portillo [32], pp. 54-58; Cubano Iguina [48], p. 172.

54 Francisco R. Goenaga Los sepultureros de España en Puerto Rico, Puerto-Rico, Imprenta de Boada y Comp., 1899, p. 18.

55 La Correspondencia, 25 de julio de 1899. 


\section{CONCLUSIONES}

Las expectativas de identidad con los Estados Unidos que se desarrollaron entre la mayoría de los criollos, incluyendo al líder liberal Luis Muñoz Rivera, no implicaban un cambio fundamental de trayectoria política ${ }^{56}$. La misma racionalidad que había prescrito la aceptación de la nacionalidad grande bajo el dominio español, aconsejaba adherirse a la nueva metrópoli. La experiencia bajo España había sido formativa. Elzaburu Vizcarrondo elaboró la conferencia de 1889 sobre el concepto de nacionalidad con un ojo puesto en la España regional y multilingüe, y otro en la amplia gama de posibilidades que había estado a la disposición de los "constructores" de nación en la tradición burguesa europea que le servía de referencia. Observó que las naciones se fundaban por acuerdo constitucional (aludiendo a las ejemplarmente multiculturales Suiza y Bélgica) y se consolidaban con la educación de las masas ${ }^{57}$. Rosendo Matienzo Cintrón también manifestaba desde la década de 1880 ese calculado distanciamiento analítico respecto del tema de la nación ${ }^{58}$.

Tampoco era contradictorio que en poco tiempo la imagen de España se desprendiese de los aspectos más conflictivos de la última etapa del régimen español. Pronto se comenzará a proyectar otra vez la España de "la raza fuerte" que, según lo hizo notar Cayetano Coll y Toste, pudo resistir a los godos (venidos del Norte) y a los árabes (venidos de Africa) y absorberlos en un fructífero proceso de mestizaje $^{59}$. Una España imaginaria, tradicional y heroica, será punto de apoyo de uno de los frentes políticos más conservadores de los criollos, frente hispanocriollo que Coll y Toste anticipaba en aproximadamente 1915: "surgirán los lazos de simpatía y amor entre los puertorriqueños y los peninsulares, hombres muy afines por la sangre, la religión, las costumbres y el idioma." 60 La mayoría de los puertorriqueños de esos años (trabajadores de la caña, campesinos, mujeres y otros sectores de opinión) se encontraba librando batallas de otra índole y atajando dificultades, según tocase para la subsistencia emocional y material cotidiana.

\footnotetext{
56 Ver afirmaciones de Muñoz Rivera en Aarón Gamaliel Ramos [48], p. 62.

57 ElZaburu VizCARRONDO [14], p. 290;

58 Ver citas en DíAz SolER [2], p. 37.

59 Edna Coll [10], p. 51.

60 Boletín Histórico de Puerto Rico, v. 6, p. 31.
} 
Los criollos de fin de siglo aportaron su grano de arena en la formación, también finisecular, del discurso de la unión de la familia hispana $^{61}$. Consolidaron tópicos que eventualmente se percibieron de forma variada: subordinadores (como la persistencia de tradiciones y costumbres respecto a la mujer) o liberalizadores (como el derecho a la lengua materna en el sector de la enseñanza y las letras). Para los criollos el lenguaje de la España heroica y la raza fuerte siempre fue, en definitiva, una herramienta de uso múltiple. Era fuente de inspiración para su lucha contra el colonialismo, o contra el conjunto de injusticias percibidas en el dominio español y que eran su razón de ser como grupo. Era fuente de autoestima y justificación de preponderancia social. Como elemento integrador anticolonialista es posible que se adecuase poco y mal a la diversa constitución cultural y racial de la isla, pero es difícil conjeturar al respecto. Si por un lado la noción de "raza" española era excluyente y ambigua, prestándose a manifestaciones de supuesta superioridad biológica y cultural "blanca"62, por otro lado, hay que reconocer que empezó a proyectarse una asimilable España mestiza, fortalecida precisamente por el mestizaje.

At the end of the $19^{\text {th }}$ Century, the evocation of a "heroic" and "hidalga" Spain was a commonplace in the writings of the Porto Rican Creoles. This image acted both as a source of inspiration for their greatest achievements, and as a source of legitimation for their power ambitions within the colonial society. At the same time, from a regenerationist and critical viewpoint the Creoles condemned a second image of Spain, that of the privileges and the oligarchies. They assumed themselves as both Spaniards and Spain-loving; nevertheless, through racist assumptions regarding and alledged Anglosaxon superiority they also accepted the new colonial domination under the United States as a duty imposed by reason.

61 Para el hispanoamericanismo regeneracionista español ver Antonio NiÑo RoDRÍGUEZ, "Hispanoamericanismo, regeneración y defensa del prestigio nacional (18981931)" en Pedro PÉrez Herrero y Nuria TABANERA, eds., EspañalAmérica Latina: Un siglo de políticas culturales, Madrid, AIETI, 1993, pp. 15-48.

62 Ver Carlos SerRano, "Miguel de Unamuno y Fernando Ortiz. Un caso de regeneracionismo trasatlántico" Nueva Revista de Filología Hispánica, v. XXXV, núm. 1 (1987), pp. 306. 